\title{
4. Family diversity in a configurational perspective
}

\author{
Eric D. Widmer
}

\section{INTRODUCTION}

This chapter stresses the contributions a configurational approach can make to improving our understanding of family diversity; i.e., the heterogeneity of families in contemporary societies. Until the 1970 s, most sociological research, inspired by structural-functionalist theory, defined significant family units as nuclear, and focused on groups composed of two heterosexual parents and their biological offspring living under the same roof (Parsons and Bales 1955). According to this theory, the nuclear family was associated with the breadwinner model, in which a strict division of paid and unpaid labour rendered gender and generational inequalities functional for society (Pfau-Effinger 2004). But, beginning in the 1970s, scholars challenged the assumption that family households function in isolation from their broader kinship networks, and stressed the diversity of exchanges with family members living elsewhere (Adam 1970; Furstenberg 2020). Since then, however, most researchers have continued to identify significant family units by the composition of households: i.e., single- or lone parent families are defined as those in which one parent lives with her child without the other parent present in the household; and stepfamilies are defined as those in which the biological parents of a child do not live together, and the resident parent has a new co-resident partner. Likewise, same-sex families have been defined as those in which two adults of the same sex live together while caring for a co-resident child. The frequency of situations in which children do not live with one of their biological parents, or live with a non-biological parent, has been extensively used as an indicator of family diversity. By contrast, I present in this chapter a configurational approach of family diversity that focuses on the interdependencies of family members in order to map family diversity. First, I describe some key dimensions of the configurational perspective on families. Second, I provide empirical results concerning the configurational diversity of families of individuals in middle adulthood and in later life. I conclude by offering some thoughts on the future of configurational studies on the family.

\section{A CONFIGURATIONAL PERSPECTIVE ON FAMILY DIVERSITY}

In a series of books and articles published from the 1930s up to the 1990s, sociologist Norbert Elias argued in favour of a perspective that approaches social groups as configurations. A few of the central points of this perspective were later stressed as critical for family research (Widmer 2010). Configurations were defined by Elias as 'webs of interdependencies formed among human beings and which connects them: that is to say, a structure of mutually oriented and dependent persons' (Elias 1978, p. 45). Being interdependent means that individuals have 
power over each other in the relationship; that is, that the practices or decisions of one family member has important consequences for the others by expanding or limiting their agency. Individuals are interdependent in a family configuration because each one fulfils some of the others' needs for emotional support, financial and practical resources, and social recognition. It may be argued that this focus on needs and resources takes us back to the time where structural-functionalist analysis dominated the field of family research, and made it impossible for researchers to understand any alternative to the nuclear family and its gender order (see Sigle in this volume). This is without considering that even when such configurations were oriented towards fulfilling their members' needs, they are not and never were peaceful cohesive groupings. Their members do not pursue the same overarching goals, and never fully internalise their expected roles in the family group (Demo and Allen 1996; Stacey 1990), as family practices appear to have a life of their own beyond social norms (Morgan 2011). Early family sociology research revealed that due to family conflict, the needs of family members for emotional support and companionship are never fully met (Sprey 1971). Indeed, rather than being seen as cohesive, bounded groups, families can be considered process-oriented networks of interdependencies in which individuals cooperate, but also hinder each other because of the social stress generated by the necessity of sharing existing resources (Widmer 2016). Thus, family configurations have to deal with power issues: i.e., a family's resources in terms of time, money, sociability, or support are scarce, and individual family members both cooperate and compete for these resources. This competition creates family tensions and conflicts, which are often beyond the control of the individual. Thus, the pattern of interdependencies that characterises family configurations is largely unintended by the individual members. In turn, these large configurations of ties shape the cooperation and the conflicts that occur in each dyad that belongs to these configurations, which makes it difficult to understand spousal or parent-child relationships independently.

Although the issue of the functions of families is often regarded by sociological scholarship as gender-biased and outdated, it has an undeniable relevance when such functions refer to individual needs, rather than the contribution of the family to society. The configurational perspective challenges the conventional approach, which defines families by focusing on the household unit. In characterising families, this approach places too much emphasis on family as a cohesive group, and too little on how various individuals create configurations of functional interdependencies beyond household units by their daily practices and interactions. In other words, exclusively using household composition to identify family units and to study family diversity disregards the complexity of family processes and family interdependencies. For instance, in a review of stepfamily research, Cherlin and Furstenberg (1994) reported that empirical research conducted in the United States showed that a majority of children whose parents separated defined their significant family members in full or partial contradiction to household membership. Overall, research on stepfamilies has stressed the variety of relational arrangements that exist both within households and in connection with external family members (Ganong and Coleman 2012). In addition, attempts to capture family diversity by listing a variety of household structures have not been successful, as the combination of criteria associated with living arrangements, especially those involving children, made it impossible to identify a reasonable number of types that are homogeneous in relational terms (Mattessich and Hill 1987). After all, as Burgess and Locke (1945) stressed in their seminal book, family interactions, or interdependencies, matter most in family research. Therefore, rather than using household composition as the decisive criterion when examining family diversity, the configu- 
rational perspective focuses its research project on patterns of interdependencies, both positive and negative, that link individuals in families.

Research on family diversity from a configurational perspective starts with the assumption that what makes a family is that the individual members co-construct a feeling of being part of a family 'we' or 'we-ness' (Castrén and Widmer 2015; Elias 1994; Kellas 2005). Such a 'we' is based on the individual members' feelings of intimacy with other family members, and the mutual commitments they develop over time (e.g., Weeks 2007). There is a growing emphasis in family research on different family configurations that serve as alternatives to the nuclear family, as defined by marriage and household membership (e.g., Budgeon and Roseneil 2004; Widmer 2010; Widmer and Jallinoja 2008). The ways in which these configurations embody the mechanisms of the identification and the inclusion of family members are receiving greater attention. To understand how the process of identifying with a family group unfolds, a series of configurational studies asked focal individuals to identify their significant family members (Widmer et al. 2013). The term 'family' was deliberately left undefined in order to elicit each respondent's personal definition of the family. Each participant was instructed that the term 'significant' should be used to refer to the individuals in his/her family who had played a role, either positive or negative, in his/her life during the past year. The respondent was then asked to provide a detailed description of his/her ties with, as well as a sociodemographic profile of, each of these family members.

\section{FAMILY WE-NESS IN MIDDLE ADULTHOOD}

In a study based on a random sample of 300 women aged 30 to 55 who had children and a co-resident partner who was not, in half of the cases, the father of the children, each participant was asked to list all significant family members, and describe her family ties with each of them; i.e., whether the family member was a partner, a biological child, a brother, a sister, etc. (Aeby et al. 2014). Almost all of the respondents included their children (98 per cent) and their current partner (96 per cent) as significant family members. In addition, more than three-quarters ( 76 per cent) of respondents referred to their mother as a significant family member, and large shares listed their father and their siblings as significant family members. Thus, individuals who were related to the respondent by blood were included first on the list of significant family members, right after the respondent's (married or unmarried) partner. In-laws were generally mentioned after blood relatives: the mother-in-law was listed as a significant family member by 37 per cent of respondents, and the father-in-law was listed by 22 per cent. In addition to blood and in-law connections, female friends were often listed as family members ( 29 per cent). Interestingly, 42 per cent of the respondents in a stepfamily household listed their former partner (i.e., the father of the target child) as a significant family member. This variety of definitions of family we-ness was encapsulated in a typology of family configurations based on cluster analysis that led to the identification of seven types.

- Friend configurations were focused on individuals who were considered by the respondent to be family members even though they were not related to the respondent by blood or by marriage or partnership. On average, such configurations included 2.78 female friends and 0.64 male friends. 
- In-law configurations were strongly oriented toward the respondent's partner and in-laws. The partner, the mother of the partner, and other in-law relationships were overrepresented in these clusters. In-laws were defined not only by marriage, but as the parents or siblings of the cohabiting partner.

- Sibling (brother and sister) configurations included the respondent's siblings and their children and current partners. Kinship configurations included a variety of individuals related by blood and marriage to the respondent, such as her partner, parents, children, uncles, aunts, nieces, nephews, cousins, and grandparents.

- Beanpole configurations referred to families in which several generations co-existed, but with only a few family members belonging to each of them (Bengtson et al. 1990). These configurations were focused on blood relatives, and included members of various generations, particularly grandparents from both the mother's and the father's sides. Whereas the sibling configurations were horizontally oriented, these arrangements were vertically oriented.

- Nuclear configurations were almost exclusively centred on the respondent's partner and children. These configurations corresponded to a definition of the family as a co-residential unit, and were based on a more exclusive than inclusive definition of family we-ness.

- In contrast, post-divorce configurations were based on a highly inclusive definition of family we-ness. These configurations included both the previous partner's and the new partner's relatives: e.g., the new partner's children, the ex-partner's parents, and, in some cases, the new partner's ex-partner or the ex-partner's new partner. In-depth qualitative analysis revealed that the inclusion of these family members resulted from frequent interactions. For instance, the respondent and the ex-partner of the new partner may have been linked because they were meeting regularly to transfer children from one household to the other (Castrén and Widmer 2015).

- Without partner configurations were only found in stepfamily households. These respondents did not include their present co-resident partner as a significant family member.

To summarise, identifying the individuals who belong to a family we, and the extent to which this we-ness is inclusive by going beyond the individuals living in the household (Castrén 2019; Castrén and Widmer 2015), makes it possible to understand family diversity in middle adulthood in reference to individual agency.

\section{WE-NESS AND FAMILY INTERDEPENDENCIES}

The concept of interdependence, which is central in configurational studies, leads researchers to focus on the relationships or practices through which a person fulfils some important function for another person. The level of dependence describes the degree to which an individual relies on an interaction partner, whereas the mutuality of dependence describes the degree to which two individuals are equally dependent on one another (Rusbult and Van Lange 2003). Indeed, interdependent individuals may not be equally dependent on each other, as the levels and types of constraints each family member can place on another family member's practices depends on the resources and needs of both. While living in the same household constitutes an interdependency, this situation does not capture all financial, practical, or emotional interdependencies that may link individuals to family members. The configurational perspective 
posits that families are best defined not as household units, but as configurations of interdependencies among individuals residing in a variety of locations (Schneider and Meil 2008) who benefit from each other's support and assistance.

There are various ways to study interdependencies in configurations. For example, the social network literature offers methodological tools that can be used to operationalise configurations (e.g., Scott 1988; Scott and Carrington 2011). By asking respondents to report the alters who regularly see each other, and who provide each other with financial or practical support, social network methods provide efficient ways to collect a large amount of data on family interdependencies (Widmer et al. 2013). Distinct patterns of family interdependencies stemming from a similar household structure can be extensively researched using the tools of social network analysis (Carrington et al. 2005; Wasserman and Faust 1994). Emotional support is described as the ability to provide guidance and moral comfort. It is usually investigated with questions such as who gives instrumental support to X; meaning which individuals are included in the family we when the family faces routine or minor troubles. In cognitive network research (Brands 2013), respondents are frequently asked to evaluate not only their own relationships with their family members, but the relationships among all family members (Widmer et al. 2013). Social network methods further permit the visualisation of exchanges of support that occur in family configurations. Sociograms such as those shown in Figures 4.1 and 4.2 provide a simple and insightful way of representing a large amount of relational information concerning family configurations. In such sociograms, the arrows point to the resource person; that is, the person a family member would ask for support when needed.

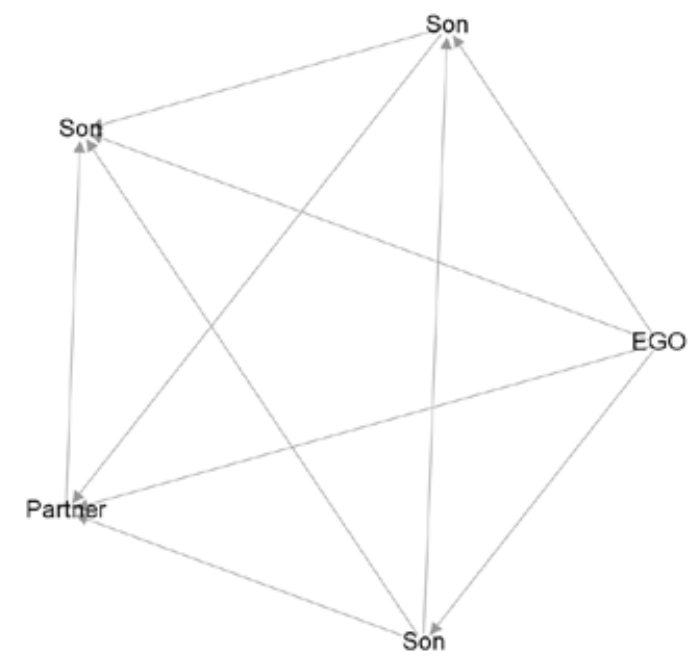

Source: Own representation.

Figure 4.1 Emotional support in a nuclear family configuration

Two distinct patterns of interdependencies were identified by previous research on family configurations: namely, one pattern in which bonding social capital predominates, and a second pattern characterised by a large amount of bridging social capital. Bonding social capital refers 
to networks with a high density of relationships between members, and in which most, if not all, individuals belonging to the network are connected because they know each other and interact frequently. Due to the collective nature of normative control and social support within such networks, expectations, claims, obligations, and trust among the individual members tend to be high (Coleman 1988). If any network member fails to conform to the expectations of the others, s/he will likely be jointly challenged by several other network members. Bonding social capital is illustrated in Figure 4.1, which features a stepfamily configuration in which almost every member is supportive of every other member.

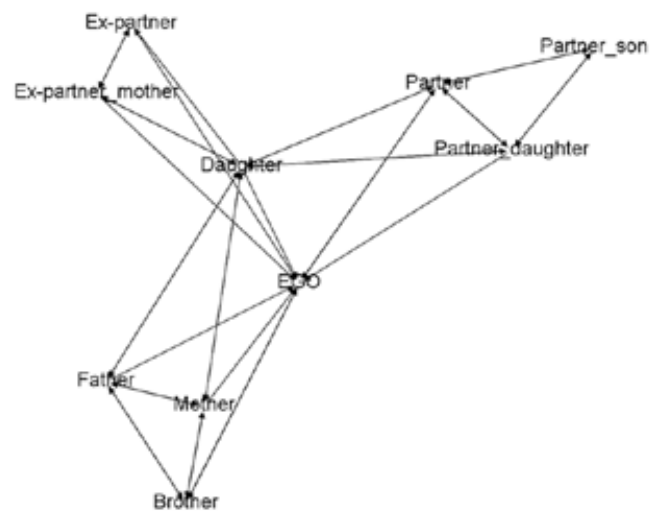

Source: Own representation.

Figure 4.2 Perceived emotional support in a post-divorce family configuration

Bridging social capital is an alternative to bonding social capital based on brokerage opportunities that some individuals develop in networks (Burt 1992; Granovetter 1973). The absence of certain connections creates relational holes in the network that provide some individuals, known as brokers, with opportunities to mediate the flow of information among members, and, therefore, to control and influence others. Figure 4.2 illustrates another stepfamily configuration in which the respondent and her daughter play a brokerage role that connects the current partner and a female friend to the rest of the network members. These individuals take advantage of being intermediaries between other individuals who are otherwise not directly connected to each other in order to develop more autonomy and agency in various contexts (Davidsson and Honig 2003; Szreter and Woolcock 2004).

Interestingly, both this configuration and the other family configurations presented stem from a similar household: each of the two focal individuals reporting on their family interdependencies was living with her biological children and a partner who was not the biological parent of her children. Even though both of these respondents had children and went through processes of separation and repartnering, they developed distinct ways of organising their family interdependencies. The first individual listed as her significant family members her three sons - one from a previous relationship and two from her current relationship - and her partner. Thus, despite her divorce and remarriage, she included in her family only individuals from her current nuclear family, and perceived these family members as having strong interdependencies that led to the development of bonding social capital. 


\section{FAMILY WE-NESS IN LATER YEARS}

How does family we-ness unfold after retirement? Individuals in this life stage often develop significant relationships with specific family members with whom they do not share a residence. Indeed, scholars have observed that older adults frequently have intimate relationships with, for example, their siblings, their nephews and nieces (Connidis 2010), and their adult children (Bengtson 2001). Having divorced earlier in life may disrupt parent-adult child relationships, and is likely to account for some of the variations in family interdependencies in later years (Shapiro Cooney 2007). Some individuals might disengage from relationships with their children and grandchildren, and compensate for the loss of these relationships by considering emotionally invested friends as belonging to their family realm (van Tilburg and Thomése 2010). These trends suggest that the diversity of family configurations may be as great in later years as it is in previous life stages. This hypothesis was tested in the VLV (Vivre/Leben/Vivere) study, a large, interdisciplinary survey on the living and health conditions of people aged 65 and older in Switzerland (Oris et al. 2016). The respondents in this study were limited to listing a maximum of five significant family members. Overall, 70 per cent of the respondents listed their children, while 46 per cent listed their current partner among their significant family members. A minority of respondents extended their significant family configuration to distant relatives by including cousins. In-laws were also sometimes added to the list of significant family members, with daughters-in-law included by 9 per cent and sons-in-law included by 7 per cent of respondents. Moreover, 21 per cent of respondents listed female friends and 14 per cent of respondents listed male friends as significant family members. Thus, voluntary kin (Braithwaite et al. 2010) - that is, people who are considered family, but are unrelated by either blood or marriage - appear to be present in all age groups. These findings suggest that older people often have significant family relationships that extend well beyond their household or their nuclear family. In order to capture the various logics behind family diversity in a configurational perspective, another typology was constructed that features no less than five configuration types that go beyond the nuclear family (Girardin and Widmer 2015). For example, the respondents in sibling configurations listed their siblings as significant family members. In such configurations, sisters were more likely to be included than brothers, while the siblings' partners and children were rarely included. The respondents in kinship configurations showed a strong orientation towards having relationships with a variety of kin, such as cousins, nephews or nieces, or non-voluntary kin. This configuration was characterised by relationships with a great diversity of family members, ranging from people related to the respondent by blood or marriage, such as in-laws, cousins, or nephews/ nieces; to non-related people, such as stepchildren, godchildren, or close friends. In addition, in a relatively large number of cases, the respondent named no one as a significant family member.

\section{THE LIFE COURSE FACTOR}

We now turn to the life course as a factor in family diversity from a configurational perspective. The constitution of family we-ness depends to a large extent on how individuals have constructed their life trajectories (De Carlo et al. 2014; Widmer 2010). Indeed, family we-ness is the result of a long-term cumulative process in which the effects of various decisions con- 
cerning marriage, fertility, separation, and divorce - but also migration, health, and career - play out. Widowhood, separation, and divorce are associated with a reorganisation of family interdependencies (Silverstein and Giarrusso 2010). Having gained some autonomy, widowed and divorced people tend to have more extended kin and friends in their networks than married people (Cornwell 2011). Compared with married people, widowed people are more likely not only to develop relationships with siblings and to make new friends, but to receive support from them (Ha 2008). Therefore, the family configurations of widowed and divorced people tend to be more heterogeneous. As divorced men are at particularly high risk of losing significant interdependencies with their children, they sometimes seek to compensate for such losses by investing in other interdependencies, such as with siblings or friends (Campbell et al. 1999). Childless individuals also tend to invest in alternative family interdependencies, such as relationships with siblings or extended kin, or with friends who are seen as family members because they represent an important source of emotional support (Schnettler and Wöhler 2013).

The family configurations of older people are shaped directly by such trends. In the VLV study (Girardin et al. 2018), the respondents in the nuclear family configuration were disproportionately male, native born, in good functional health, and higher income; and were more likely to have children and a partner. The respondents in the sibling family configuration were disproportionately male, native born, in good functional health, and higher income; and were more likely to have a partner and siblings, but no children. By contrast, the respondents in kinship and sparse family configurations tended to be childless and without a partner or siblings; and were disproportionately female, foreign born, in poor functional health, and lower income. Because of gender differences in life expectancy, the older men were more likely to have a partner than the older women, and were thus more likely to be in a nuclear family configuration. The study found other marked gender differences as well. For example, men who were single, divorced, or widowed were more likely to be in a sparse family configuration than their female counterparts. Divorced men were especially likely to be in such a configuration. It therefore appears that men who had no partner were at particularly high risk of disengagement from different kinds of relatives. Overall, the active creation of family configurations by individuals in later years was bounded by a set of structural factors stemming from their life paths. Gender, income, health status, and, above all, demographic outcomes contributed to the accumulation of advantages and disadvantages over the life course (Dannefer 1987), and these processes, in turn, resulted in a variety of family configurations.

Thus, it appears that the composition of family configurations is the end result of a large number of decisions people make across the life course: e.g., getting married, having children, and getting divorced. Following the linked lives principle (Elder 1994), family diversity is also affected by the decisions made by other family members: e.g., whether a person has siblings or grandchildren depends on decisions made by his/her parents and children. As each person's life course is shaped by interactions within families (Blossfeld and Drobnič 2002), family configurations are beyond the direct grasp of any individual. It should, however, be emphasised that family configurations are more than just the product of a set of past decisions. Family we-ness is also relational and symbolic in nature. For example, when a person does not consider individuals related to him/her by co-residence, blood, or marriage as family, s/he is creating a social distance from them that has a variety of consequences. This person is likely to have fewer trusting relationships s/he can turn to for help or for regular social interactions. By contrast, when a person considers individuals who are unrelated to him/her by co-residence, 
blood, or marriage as family, s/he is developing a set of functional interdependencies that go well beyond those expected in friendship.

Family configurations are generated by agentic individuals who face constraints related to their life course. As the life course has pluralised, life trajectories have become increasingly heterogeneous in cohorts born after the 1960s (Brückner and Mayer 2004; Demo et al. 2000; Elzinga and Liefbroer 2007). Accordingly, individuals are confronted with new constraints and new opportunities when building up their family configurations. In some cases, even people with highly complex family trajectories develop a small, closely knit, and bounded family configuration that resembles a nuclear family. By contrast, other people develop open family configurations by including friends, in-laws, or remote blood kin in their pool of significant family members. There is still much to be learned about the connections between the characteristics of life trajectories and the development of family configurations. Migration and health trajectories, as well as work trajectories, may have important effects on family configurations that are not yet well understood. Previous configurational analyses have focused on the impact of family events and family transitions on family configurations, and have underemphasised the impact of spill-over effects across life domains (Spini et al. 2017).

\section{FAMILY DIVERSITY AND AMBIVALENCE}

Differences in the social capital produced by families is only one reason why families are diverse. Debates about the sources of family diversity in the field of social gerontology have centred on the role of intergenerational solidarity and conflict within the family realm, with scholars ultimately reaching a consensus regarding the dialectical rather than the oppositional nature of family dynamics that emphasises contradictions within families, their unexpected consequences, and the need for change (Lüscher 2002). When family members lack the necessary resources to live up to expectations that they will provide each other with support, and remain in close proximity, various ambivalences may be triggered (Connidis and McMullin, 2002). In configurational terms, ambivalence has been defined as the co-presence in a single family configuration of positive and negative interdependencies that could create relational imbalances (Girardin et al. 2018; Widmer and Lüscher 2011). Thus, the focus of configurational research is not only on how social inequalities create stress in families, but on how the organisation of family ties beyond the household can put pressure on family members (Connidis and Barnett 2018).

Various studies have shown that when brothers and sisters need to cooperate to provide care for their older parents, there is often a high level of ambivalence between the adult children and their elderly parents, as well as between the siblings. The composition of family configurations seems to play a key role in the development of ambivalence in families. The family configurations of older adults that are focused on their children, their partner's children, their children's partners, and their children's children tend to be characterised by high levels of ambivalence (Ward 2008), especially when the family members lack financial resources or are in poor health. In such cases, the scarcity of resources can make it difficult for older parents and their adult children to meet their obligations to support each other (Offer 2012). Family configurations are more likely to be characterised by supportive relationships and low levels of conflict when the members have sufficient resources - such as good health, higher income levels, and solid partnerships - to sustain supportive exchanges and to share care responsibil- 
ities within the family network (Girardin et al., 2018). Conversely, in family configurations in which children are absent, and those included in the family network participate voluntarily, levels of conflict tend to be low (Campbell et al. 1999; Schnettler and Wöhler 2013). In such family configurations, older adults are better able to maintain satisfying and supportive interdependencies, while disengaging from tense relationships. However, the family interdependencies of childless older adults can also be weak or non-existent because they are not sustained by strong obligations to provide support. Overall, the positive interdependencies within family configurations are often accompanied by tensions or conflicts when resources are lacking and the functional health of the elderly family members is poor. These patterns differ between men and women. Women are more likely than men to experience ambivalence because they are at greater risk of experiencing declines in income and in functional health, and are under much stronger normative pressure to perform family work (Connidis and Barnett 2018).

\section{CONCLUSION}

In order to better capture family diversity, sociology should go beyond systems of classification based on household composition, such as whether a family is a nuclear family, a stepfamily, a lone-parent family, or a same-sex family. Those classifications reinforce the importance of the nuclear family model by using it as an implicit reference, and by disregarding the relational diversity that exists within each of these household structures. Rather than using the household and its composition as a yardstick to operationalise a family unit, scholars should pay attention to configurations of family interdependencies that individuals actively help to create and sustain over the life course (Zartler and Grillenberger 2017). From young adulthood to old age, a set of configurational types captures various ways of defining family we-ness with distinct logics of inclusivity. When family diversity is considered from a configurational perspective, it looks different than it does when the composition of households is the starting point of research. Indeed, two individuals belonging to dissimilar households - one who is married and living with her children and their father, and another who is divorced and living with her children and a new partner - may be embedded in similar configurations of interdependencies because they define their family we-ness in similar ways. Alternatively, two individuals can live in similar households but develop very different definitions of family we-ness and configurations of interdependencies based on their past life course decisions and the symbolic meaning that they associate with 'family'. Overall, the reviewed evidence suggests that the diversity of family we-ness is based on a few major kinship criteria (Furstenberg 2020): blood; partnership (through marriage or cohabitation); friendship; and the interaction between partnership and blood, as in the case of in-laws or step-relatives.

The configurational perspective provides concepts and tools that add to our understanding of family diversity by going beyond the composition of households. There is much to be learned about the various definitions of family we-ness and the logics of the development of family interdependencies (Castrén 2019). The agency of each member is consequential, as it shapes family configurations beyond the confines of households. Greater efforts should be made to understand these configurations, and how personal resources contribute to them, as such findings could shed light on how family clashes (intergenerational ambivalence, couple conflict, and violence), as well as family solidarity, develop. From this perspective, family diversity should be studied based not primarily on differences in household structures, but on 
how the interdependencies of family members within and beyond the household are organised (Furstenberg 2020). Specifically, family solidarity and family conflict should be researched in connection with such chains of interdependencies and family identification.

A configurational perspective on families is based on the assumption that family diversity is a product of the actors' agentic actions in response to constraints that an increasingly uncertain world places on them. Indeed, as the social and cultural salience of the nuclear family and its associated breadwinner model weaken, the welfare state erodes, and economic hazards mount, investigating family we-ness and chains of family interdependencies is becoming increasingly relevant. Rather than stressing the distinctiveness of particular family structures based on household criteria, sociologists should try to better understand the diversity of family we-ness, and the consequences that these different configurations have for the interdependencies that link individuals together in society. By using the large number of tools that social network analysis has to offer (Scott 1988; Scott and Carrington 2011), scholars are well equipped to investigate the diversity of families in contemporary society.

\section{REFERENCES}

Adams, B.N. (1970), 'Isolation, function, and beyond: American kinship in the 1960s', Journal of Marriage and Family, 32 (4), 575-97. doi:10.2307/350252.

Aeby, G., E.D. Widmer, and I. De Carlo (2014), 'Bonding and bridging social capital in step-and first-time families and the issue of family boundaries', Interpersona: An International Journal on Personal Relationships, 8 (1), 51-69. doi:10.5964/ijpr.v8i1.149.

Bengtson, V.L. (2001), 'Beyond the nuclear family: The increasing importance of multigenerational bonds (the burgess award lecture)', Journal of Marriage and Family, 63, 1-16. doi:10.1111/j .1741-3737.2001.00001.x.

Bengtson, V.L., C. Rosenthal, and L. Burton (1990), 'Families and aging: Diversity and heterogeneity', in R.H. Binstock and L. George (eds), Handbook of Aging and Social Sciences, San Diego, CA: Academic Press, pp. 263-87. doi:10.1016/B978-0-12-088388-2.X5000-7.

Blossfeld, H.-P. and S. Drobnič (2002), Careers of Couples in Contemporary Society: From Male Breadwinner to Dual-Earner Families, New York: Oxford University Press. doi:10.2307/3089834.

Braithwaite, D.O., B.W. Bach, L.A Baxter, R. DiVerniero, J.R. Hammonds, A.M. Hosek, E.K. Willer, and B.M. Wolf (2010), 'Constructing family: A typology of voluntary kin', Journal of Social and Personal Relationships, 27 (3), 388-407. doi:10.1177/0265407510361615.

Brands, R.A. (2013), 'Cognitive social structures in social network research: A review', Journal of Organizational Behavior, 34 (S1), S82-S103. doi:10.1002/job.1890.

Brückner, H. and K.U. Mayer (2004), 'The de-standardization of the life course: What it might mean? And if it means anything, whether it actually took place?', in R. Macmillan (ed.), The Structure of the Life Course: Standardized? Individualized? Differentiated? Advances in Life Course Research, Vol. 9, Amsterdam: Elsevier, pp. 27-54.

Budgeon, S. and S. Roseneil (2004), 'Editors' introduction: Beyond the conventional family', Current Sociology, 52 (2), 127-34. doi:10.1177/0011392104041797.

Burgess, E.W. and H.J. Locke (1945), The Family: From Institution to Companionship, Knoxville, TN: American Book Co.

Burt, R. (1992), Structural Holes: The Social Structure of Competition, Cambridge, MA: Harvard University Press.

Campbell, L., I.A. Connidis, and L. Davis (1999), 'Sibling ties in later life: A social network analysis', Journal of Family Issues, 20, 114-48. doi:10.1177/019251399020001006.

Castrén, A.M. (2019), 'Becoming "us": Marital name, gender, and agentic work in transition to marriage', Journal of Marriage and Family, 81 (1), 248-63. doi:10.1111/jomf.12519.

Castrén, A.M. and E.D. Widmer (2015), 'Insiders and outsiders in stepfamilies: Adults' and children's views on family boundaries', Current Sociology, 63, 35-56. doi:10.1177/0011392114551650. 
Cherlin, A.J. and F.F. Furstenberg (1994), 'Stepfamilies in the US: A reconsideration', Annual Review of Sociology, 20 (1), 359-81. doi:10.1146/annurev.so.20.080194.002043.

Coleman, J.S. (1988), 'Social capital in the creation of human capital', American Journal of Sociology, 94, 95-120. doi:10.1086/228943.

Connidis, I.A. (2010), Family Ties and Aging, 2nd edition, Thousand Oaks, CA: Pin Forge Press/Sage.

Connidis, I.A. and A.E. Barnett (2018), Family Ties and Aging, London: Sage.

Connidis, I.A. and J.A. McMullin (2002), 'Sociological ambivalence and family ties: A critical perspective', Journal of Marriage and Family, 64 (3), 558-67. doi:10.1111/j.1741-3737.2002.00558.x.

Cornwell, B. (2011), 'Independence through social networks: Bridging potential among older women and men', Journals of Gerontology Series B: Psychological Sciences and Social Sciences, 66, 782-94. doi:10.1093/geronb/gbr111.

Dannefer, D. (1987), 'Aging as intracohort differentiation: Accentuation, the Matthew effect, and the life course', Sociological Forum, 2, 211-36. doi:10.1007/BF01124164.

Davidsson, P. and B. Honig (2003), 'The role of social and human capital among nascent entrepreneurs', Journal of Business Venturing, 18 (3), 301-31.

De Carlo, I., G. Aeby, and E.D. Widmer (2014), 'La variété des configurations familiales après une recomposition: Choix et contraintes', Revue Suisse de Sociologie, 40 (1), 9-27.

Demo, D.H. and K.R. Allen (1996), 'Diversity within lesbian and gay families: Challenges and implications for family theory and research', Journal of Social and Personal Relationships, 13 (3), 415-34.

Demo, D.H., K.R. Allen, and M.A. Fine (2000), Handbook of Family Diversity, Oxford: Oxford University Press.

Elder, G.H., Jr. (1994), 'Time, human agency, and social change: Perspectives on the life course', Social Psychology Quarterly, 57, 4-15. doi:10.2307/2786971.

Elias, N. (1978), What Is Sociology, London: Hutchinson.

Elias, N. (1994), The Civilizing Process, Oxford: Basil Blackwell.

Elzinga, C.H. and A.C. Liefbroer (2007), 'De-standardization of family-life trajectories of young adults: A cross-national comparison using sequence analysis', European Journal of Population, 23, 225-50.

Furstenberg, F.F. (2020), 'Kinship reconsidered: Research on a neglected topic', Journal of Marriage and Family, 82 (1), 364-82. doi:10.1111/jomf.12628.

Ganong, L.H. and M. Coleman (2012), Stepfamily Relationships, New York: Springer. doi:10.1007/978 -I-4899-7702-1.

Girardin, M. and E.D. Widmer (2015), 'Lay definitions of family and social capital in later life', Personal Relationships, 22 (4), 712-37. doi:10.1111/pere.12107.

Girardin, M., E.D. Widmer, I.A. Connidis, A.M. Castrén, R. Gouveia, and B. Masotti (2018), 'Ambivalence in later-life family networks: Beyond intergenerational dyads', Journal of Marriage and Family, 80 (3), 768-84. doi:10.1111/jomf.12469.

Granovetter, M.S. (1973), 'The strength of weak ties', American Journal of Sociology, 78, 1360-80. doi: $10.1086 / 225469$.

Ha, J.-H. (2008), 'Changes in support from confidants, children, and friends following widowhood', Journal of Marriage and Family, 70, 306-18. doi:10.1111/j.1741-3737.2008.00483.x.

Kellas, J.K. (2005), 'Family ties: Communicating identity through jointly told family stories', Communication Monographs, 72 (4), 365-89. doi:10.1080/03637750500322453.

Lüscher, K. (2002), 'Intergenerational ambivalence: Further steps in theory and research', Journal of Marriage and Family, 64 (3), 585-93. doi:10.1111/j.1741-3737.2002.00585.x.

Mattessich, P. and R. Hill (1987), 'Life cycle and family development', in Handbook of Marriage and the Family, Boston, MA: Springer, pp. 437-69.

Morgan, D.H.J. (2011), 'The original argument', in D. Morgan (ed.), Rethinking Family Practices, London: Palgrave Macmillan. doi:10.1057/9780230304680.

Offer, S. (2012), 'The burden of reciprocity: Processes of exclusion and withdrawal from personal networks among low-income families', Current Sociology, 60, 788-805. doi:10.1177/ 0011392112454754.

Oris, M., M. Nicolet, E. Guichard, C. Monnot, and D. Joye (2016), 'Surveying the elderly, capturing vulnerability: The VLV (Vivre-Leben-Vivere) survey', in M. Oris, E. Guichard, M. Nicolet, R. Gabriel, A. Tholomier, C. Monnot, D. Fagot, and D. Joye (eds), Surveying Vulnerability, Surveying 
Vulnerable Populations: Ten Experiences across the Swiss Society, New York: Springer. doi:10.1007/ 978-3-319-24157-9 2.

Parsons, T. and R. Bales (1955), Family: Socialization and Interaction Process, New York: Free Press. doi:10.1525/aa.1956.58.6.02a00150.

Pfau-Effinger, B. (2004), 'Socio-historical paths of the male breadwinner model: An explanation of cross-national differences', British Journal of Sociology, 55 (3), 377-99. doi:10.1111/j.1468-4446 .2004.00025.x.

Rusbult, C.E. and P.A.M. Van Lange (2003), 'Interdependence, interaction, and relationships', Annual Review of Psychology, 54, 351-75. doi:10.1146/annurev.psych.54.101601.145059.

Schneider, N.F. and G. Meil (eds) (2008), Mobile Living across Europe I: Relevance and Diversity of Job-Related Spatial Mobility in Six European Countries, Leverkusen Opladen: Verlag Barbara Budrich.

Schnettler, S. and T. Wöhler (2013), 'On the supporting role of friendship for parents and non-parents in later life: A comparative analysis using data from the three waves of the German aging survey', in M. Löw (ed.), Frankfurt: Campus Verlag.

Scott, J. (1988), ‘Social network analysis', Sociology, 22 (1), 109-27. doi:10.1177/0038038588022001007.

Scott, J. and P.J. Carrington (2011), The Sage Handbook of Social Network Analysis, London: Sage.

Shapiro, A. and T.M. Conney (2007), 'Divorce and intergenerational relations across the life course', Advances in Life Course Research, 12, 191-219. doi:10.1016/S1040-2608(07)12007-4.

Silverstein, M. and R. Giarrusso (2010), 'Aging and family life: A decade review', Journal of Marriage and Family, 72, 1039-58. doi:10.1111/j.1741-3737.2010.00749.x.

Spini, D., L. Bernardi, and M. Oris (2017), 'Toward a life course framework for studying vulnerability', Research in Human Development, 14 (1), 5-25. doi:10.1080/15427609.2016.1268892.

Sprey, J. (1971), 'On the management of conflict in families', Journal of Marriage and the Family, 33 (4), 722-31. doi:10.1111/j.1741-3737.2010.00727.x.

Stacey, J. (1990), New Brave Families: Stories of Domestic Upheaval in Late Twentieth Century America, New York: Basic Books.

Szreter, S. and M. Woolcock (2004), 'Health by association? Social capital, social theory, and the political economy of public health', International Journal of Epidemiology, 33 (4), 650-67.

Van Tilburg, T.G. and F. Thomése (2010), 'Societal dynamics in personal networks', in D. Dannefer and C. Phillipson (eds), The Sage Handbook of Social Gerontology, London: Sage, pp. 215-25.

Ward, R.A. (2008), 'Multiple parent-adult child relations and well-being in middle and later life', Journals of Gerontology Series B: Psychological Sciences and Social Sciences, 63 (4), S239-S247. doi:10.1093/geronb/63.4.S239.

Wasserman, S. and K. Faust (1994), Social Network Analysis: Methods and Applications, Vol. 8, Cambridge: Cambridge University Press.

Weeks, J. (2007), The World We Have Won: The Remaking of Erotic and Intimate Life, London: Routledge. doi: $10.4324 / 9780203956809$.

Widmer, E.D. (2010), Family Configurations: A Structural Approach to Family Diversity, London: Ashgate. doi:10.4324/9781315581903.

Widmer, E.D. (2016), Family Configurations: A Structural Approach to Family Diversity, London: Routledge.

Widmer, E.D. and R. Jallinoja (2008), Beyond the Nuclear Family: Families in a Configurational Perspective, Bern: Peter Lang.

Widmer, E.D. and K. Lüscher (2011), 'Les relations intergénérationelles au prisme de l'ambivalence et des configurations familiales', Recherches Familiales, 8 (1), 49-60. doi:10.3917/rf.008.0049.

Widmer, E.D., G. Aeby, and M. Sapin (2013), 'Collecting family network data', International Review of Sociology, 23 (1), 27-46. doi:10.1080/03906701.2013.771049.

Zartler, U. and K. Grillenberger (2017), 'Doubled homes - doubled social ties? Children's relationships in post-divorce shared residence arrangements', Children and Society, 31 (2), 144-56. doi:10.1111/ chso. 12194 . 